\title{
Variations in Pedagogical Design of Massive Open Online Courses (MOOCs) Across Disciplines
}

\section{ABSTRACT}

Given that few studies have formally examined pedagogical design considerations of Massive Online Open Courses (MOOCs), this study explored variations in the pedagogical design of six MOOCs offered at the University of Toronto, while considering disciplinary characteristics and expectations of each MOOC. Using a framework (Neumann et al., 2002) characterizing teaching and learning across categories of disciplines, three of the MOOCs represented social sciences and humanities, or "soft" MOOCs, while another three represented sciences, or "hard" MOOCS. We utilized a multicase study design for understanding differences and similarities across MOOCs regarding learning outcomes, assessment methods, interaction design, and curricular content. MOOC instructor interviews, MOOC curricular documents, and discussion forum data comprised the data set. Learning outcomes of the six MOOCs reflected broad cognitive competencies promoted in each MOOC, with the structure of curricular content following disciplinary expectations. The instructors of soft MOOCs adopted a spiral curriculum and created new content in response to learner contributions. Assessment methods in each MOOC aligned well with stated learning outcomes. In soft MOOCs, discussion and exposure to diverse perspectives were promoted while in hard MOOCs there was more emphasis on question and answer. This study shows disciplinary-informed variations in MOOC pedagogy, and highlights instructors' strategies to foster disciplinary ways of knowing, skills, and practices within the parameters of a generic MOOC platform. Pedagogical approaches such as peer assessment bridged the disciplines. Suggestions for advancing research and practice related to MOOC pedagogy are also included.

\section{KEYWORDS}

Massive Open Online Courses (MOOCs); Pedagogical design; Disciplinary differences; MOOC pedagogy

\section{PURPOSE}

Few studies have formally examined pedagogical design considerations of MOOCs. In this study we focused on deconstructing curriculum design and implementation in six MOOCs representing a range of disciplinary affiliation and then identified promising practices. The purpose of this research is to understand Massive Open Online Course (MOOC) design across disciplines with respect to four dimensions: learning outcomes, assessment of learning outcomes, interaction design, and curricular content (Neumann, Parry, \& Becher, 2002). Within existing literature, students' overall learning experience, course design, and course implementation in higher education may reflect discipline-specific 
epistemological differences. Researchers have pointed out such disciplinary differences in various dimensions of teaching practices, including fostering deep approaches to learning (Laird, Shoup, Kuh, \& Schwarz, 2008); teacher vs. learner centered instructional approaches (Lindblom-Ylänne, Trigwell, Nevgi, \& Ashwin, 2006); and assessment approaches (Jessop \& Maleckar, 2016). In the context of the University of Toronto ( $\mathrm{U}$ of $\mathrm{T}$ ), findings of a yearly report (Open UToronto MOOC Initiative: Report on Second Year of Activity, 2014) indicated differences in course design across U of T MOOCs focused on different disciplines. Computer programming courses, for example, contained more automaticallygraded assignments compared to courses in social work or aboriginal education. Motivated by these indicators and informed by existing research, this multicase study (Stake, 2013) examines variations in course design among six Coursera MOOCs from different disciplines offered by $\mathrm{U}$ of $\mathrm{T}$. As a common ground for comparison across multiple MOOCs, we use an existing framework (e.g. Neumann et al., 2002) that characterizes teaching and learning practices in different disciplines. The framework adapted here is by no means restrictive and prescriptive of how pedagogical design of a course in a given discipline should be approached, but rather, provides a useful lens for understanding and discussion across disciplines.

\section{CONCEPTUAL FRAMEWORK}

Course design and implementation in higher education may reflect discipline specific epistemological differences in various dimensions of teaching practices, including teacher vs. learner centered instructional approaches (Lindblom-Ylänne et al., 2006), assessment methods (Jessop \& Maleckar, 2016), and interaction design (Barbera, Layne, \& Gunawardena, 2014). To guide our analysis of course design, we used a disciplinary categorization framework (Neumann et al., 2002), derived from Biglan's (1973) disciplinary typology. Biglan (1973) distinguished epistemological differences between high and low paradigm disciplines with high paradigm disciplines having consensus over knowledge base and the methods of inquiry, whereas low paradigm disciplines embrace iterative cycles of knowledge construction. Rather than being restrictive and prescriptive, this framework offered a set of dimensions related to teaching and learning practices that facilitate the comparison of course design in MOOCs.

\section{Pedagogical Practices in Disciplinary Context}

Neumann et al. (2002) and Neumann (2003) proposed a framework with two dimensions of disciplinary knowledge and social practices to characterize teaching and learning across four categories of disciplines: hard pure (e.g. natural sciences), soft pure (e.g. humanities), hard applied (e.g. engineering), and soft applied (e.g. education). Three knowledge-related dimensions of Neumann's (2003) framework, briefly described below, were relevant to this study:

- Content and curriculum. Hard pure fields present structured and cumulative curricular content. Hard applied fields incorporate the application of knowledge and theories to practice. Curriculum in soft pure fields is expansive. Soft applied fields emphasize synthesis of ideas while considering their application in a professional context.

- Cognitive processes and competencies. Students develop field-specific knowledge in hard pure fields. Reasoning skills and ability to use discipline-specific methods to judge the accuracy of data are other desired student outcomes. Students in soft fields are expected to develop argumentation and critical thinking skills.

- Assessment. Hard pure fields incorporate frequent examinations to gauge students' knowledge. Problems, in hard applied fields are another form of assessment. Soft pure 
fields often incorporate analytical and argumentative essays. Formative assessment is common in soft fields. Soft applied fields include practice-related assessments.

While disciplinary differences may lead to variations in teaching approaches, trans-disciplinary pedagogical guidelines exist that promote learning for understanding. For example, incorporating formative and frequent assessments with opportunities for peer- and self-assessment has been widely recommended (Cox, Imrie, Miller, \& Miller, 2014).

\section{Variations in Teaching Approaches}

Previous studies have attended to differences in approaches to teaching and learning across disciplines and the impact of such difference on students' learning experiences (Barbera et al., 2014; Lindblom-Ylänne et al., 2006; Norton, Richardson, Hartley, Newstead, \& Mayes, 2005; Postareff, Virtanen, Katajavuori, \& Lindblom-Ylänne, 2012). Here, we provide a brief review of selected studies to showcase such variations in approaches to teaching and learning, assessment, and interaction in courses across disciplines.

To understand potential relations between disciplinary background and university instructors' approaches to teaching, Lindblom-Ylänne et al. (2006) invited 340 instructors from two countries who represented hard and soft disciplinary categories, to complete a 16-item Approaches to Teaching Inventory (Trigwell \& Prosser, 2004). The survey contained items addressing two categories of approaches to teaching: conceptual change/student-focused (CCSF), and information transmission/teacher-focused (ITTF). Within the 303 completed surveys, significant differences were observed on CCSF items among disciplinary categories, with hard category scoring lower in CCSF than soft disciplinary categories. As for ITTF items, instructors of hard disciplines scored significantly higher in these items than instructors of soft disciplines (Lindblom-Ylänne et al., 2006). Comparable findings are reported for more than 10,000 faculty members' use of deep approaches to learning in their undergraduate teaching as expressed in a Faculty Survey of Student Engagement (Laird et al., 2008), concluding that faculty members in soft disciplines were more likely to engage their students in opportunities that involved deep approaches to learning.

Regarding assessment methods, in a single discipline study, 28 instructors from a faculty of Pharmacy were asked about their beliefs regarding the purposes that assessment would serve and about their actual practice of classroom assessment (Postareff et al., 2012). The majority of the instructors expressed a knowledge reproduction conception of assessment and incorporated a limited range of summative assessment approaches in their practice. Postareff et al. (2012) also noticed an absence of self-assessment and rare use of peer-assessment. Dominant disposition and practice of assessment to measure knowledge reproduction was attributed to the characteristics of disciplinary knowledge in the field of Pharmacy. Different findings were reported, however, in a study that compared the variety of formative and summative assessment in three disciplinary groups of sciences, humanities, and professional programs (Jessop \& Maleckar, 2016). In their study, formative assessment was defined as a non-graded mandatory assessment task. Drawing on program audit data, the authors noticed that the number of formative assessment approaches in sciences courses was three times the number of formative assessments in humanities and professional programs disciplinary groups. They attributed such difference to the application of formative assessment in sciences to help students master the cumulative knowledge base of their degree program (Jessop \& Maleckar, 2016).

According to the Community of Inquiry (Garrison, Anderson, \& Archer, 2010) model, interaction in online courses manifests in at least three modes: student-content; student-instructor, and student-student. Studies that investigate disciplinary differences in integrating interaction have 
considered either a single mode or multiple modes of interaction in online courses. To probe the level of cognitive, instructional, and social presence in discussion forums of sciences and humanities courses offered in an Open University, Gorsky, Caspi, Antonovsky, Blau, and Mansur (2010) compared 25 discussion forums from science courses with 25 forums from humanities courses. Regarding the three dimensions of presence as defined by the Community of Inquiry model, humanities instructors were more active in the social presence dimension while science instructors showed higher levels of cognitive presence. Within the cognitive presence dimension, Gorsky et al. (2010) reported that science instructors posted more exploration messages compared with a higher number of triggering event posts sent by humanities instructors. The effect of instructional presence on learner participation in online discussions, however, is debated in online learning literature.

While differences in various pedagogical components of course design and implementation have been highlighted in terms of disciplinary context (Arbaugh, Bangert, \& Cleveland-Innes, 2010; Pace, \& Middendorf, 2004), the process of course design on its own is understudied within higher education (Sharpe \& Oliver, 2013). Such research is also missing in the case of pedagogical design of Massively Open Online Courses (MOOCs). Note that, in this study, we do not explore design issues related to MOOCs developed according to a connectivist approach to learning that highly emphasizes learning through social connections (Kop, Fournier, \& Mak, 2011). Rather, we focus on MOOCs that are more closely modelled on typical higher education courses.

\section{MOOC Pedagogy}

At this time, formal studies of disciplinary variations in MOOC design that allow for comparison and contrast of findings are scarce. In one study, Swan, Bogle, Day, van Prooyen, and Richardson (2014) developed a rubric to characterize MOOC development along 10 dimensions, including epistemology, teacher/student centeredness, and cognitive focus of learning activities. Applying the rubric to 13 STEM (Science, Technology, Math, \& Engineering) and four non-STEM MOOCs, Swan et al. (2014) observed differences in pedagogical approaches of the two categories of MOOCs: non-STEM courses were more student-centered and included activities that facilitated knowledge construction, rather than knowledge reproduction.

As for interaction, Chandrasekaran, Ragupathi, Kan, and Tan (2015) examined ways to maximize the benefits of instructor intervention in MOOC discussion forums. In 61 Coursera MOOCs from various disciplines, Chandrasekaran et al. (2015) observed an overall higher proportion of instructor intervention in exam-related threads compared with lecture-related threads. With expected variations in the design of MOOCs, Chandrasekaran et al. (2015) have not explained where instructors' efforts in discussion forums were concentrated, in relation to learning outcomes and disciplinary expectations.

Considering discipline-related variations across several dimensions of teaching practices, and the emergence of studies that examine pedagogical characteristics of MOOCs, further investigation of MOOC design process is compelling. The research question guiding this study is: in six $U$ of TMOOCs from different disciplines, how can course design be characterized in terms of learning outcomes, curriculum and content, assessment methods, and interaction design?

\section{STUDY DESIGN}

Using a multicase study design (Stake, 2006), we examined how U of T instructors designed six MOOCs from hard and soft disciplines. Case study design has been recognized as a conducive research strategy for Scholarship of Teaching and Learning (SoTL) inquiry (Pearson, Albon, \& Hubball, 2015). 
We used the hard/soft dimension of Neumann and colleagues' (2002) disciplinary categorization. Note that at the time when these courses were designed and delivered, Coursera, the platform used for the six MOOCs, provided a universal template for course design which may account for some similarities in course components across the six MOOCs that we present and discuss in the rest of this paper. Guided by the template, each course included content, mostly in the form of lecture videos, assessment, and discussions. The six MOOCs, identified below by a shortened version of their original titles, provided a comprehensive set to study pedagogical practices in MOOC design within this particular university context. The total number of learners enrolled in each MOOC as of October 2015 is indicated following the shortened title.

- Soft MOOCs: AboriginalEd (20,966), IntroPsych (77,608), and MentalHealth $(23,491)$

- Hard MOOCs: Programming1 (80,000), Programming2 $(53,974)$, and Stats $(48,687)$

We collected the following qualitative and quantitative data: (1) MOOC documents in Coursera (syllabus and course content); (2) Interviews with MOOC instructors; and, (3) MOOC discussion forum data. Each case was first analyzed individually. Afterwards, we conducted cross-case analysis by combining findings from each case relevant to common themes.

\section{FINDINGS}

Findings are presented in four sections: learning outcomes, curricular content, assessment methods, and interaction design.

\section{Learning Outcomes}

Each MOOC identified distinct learning outcomes, summarized below.

\section{- $\quad$ Soft MOOCs}

○ AboriginalEd: deepening understanding of aboriginal worldviews; critical thinking; and using evidence to construct arguments

IntroPsych: gaining foundational knowledge on various topics in psychology; critical thinking; active learning; and argumentation

○ MentalHealth: understanding historical background of the field; understanding the impact of contextual social/cultural issues affecting dispositions towards mental health and treatment options; and developing anti-stigma awareness

- Hard MOOCs

O Stats: gaining foundational knowledge of statistical methods and their application; and understanding strengths and weaknesses of statistical methods in context

- Programming1 and 2: Programming1, addressing computational thinking and fundamental concepts of computer programming. Programming2, focusing on style and efficiency of code

Two soft MOOCs-IntroPsych and AboriginalEd-explicitly emphasized critical thinking, argument development, and knowledge construction. These competencies can be applied beyond a single course or degree program. A main goal in AboriginalEd MOOC was to engage learners with a range of knowledge about aboriginal worldviews by delegating cognitive responsibility to MOOC learners. The course instructor explained: 
Saying this is how we are going to go about learning and understanding as a kind of a journey, then, they [learners] become responsible for ensuring that they are constantly pushing themselves. I did it more to help those who already know a lot so they are not getting bored. (Instructor interview, AboriginalEd)

Learning outcomes of Hard MOOCs were more concrete regarding discipline-related competencies and skills that the learner would gain by completing the course. Yet critical thinking was not excluded from hard MOOCs. The Stats instructor, for example, explained:

I'd much rather that students, rather than just end up with a cookbook, you know, 'I got this set of ingredients, so I look up a recipe' ... I'd rather them get some critical thinking skills about how these things are used and what they are good for. (Instructor interview, Stats)

\section{Curriculum and Content}

All six MOOCs mainly presented content via lecture videos, as prompted by the course design template provided in the Coursera platform. We examined the average length and the number of lectures in each week for all six MOOCs. While the number of weekly lectures was comparable across courses, two soft MOOCs, AboriginalEd and IntroPsych, on average had the longest total lecture time, 106 minutes and 146 minutes respectively, exceeding the average length of lectures in other MOOCs by at least 30 minutes.

Stats, AboriginalEd, and Intropsych MOOCs included optional videos: R statistical package tutorials, Screenside chats, and Side Dishes, respectively. R statistical package tutorial videos were included in course material from the beginning of the Stats MOOC and were mentioned in the "About the Course" page. Screenside chats and Side Dishes were conceptualized and created while the AboriginalEd and the IntroPsych MOOCs were offered. Document analysis and instructor interview data revealed that AboriginalEd, MentalHeath, and IntroPsych MOOC instructors expanded their curricular content through these additional videos. The videos responded to issues and questions that evolved through learners' engagement with course content and their contributions to discussion forums.

According to the IntroPsych instructor, making the instructor's reaction to the ongoing course discussions visible by publishing Side Dish videos, allowed learners who were not engaged in course discussions to become aware of important topics that had emerged from their fellow learners' contributions. Another approach, taken by the MentalHealth MOOC instructor, was to provide weekly commentary of discussions and lessons learned in the previous week.

Curricular content of soft MOOCs shared one characteristic: all three MOOCs complemented their lectures, presented by the MOOC instructor, with outside resources, including interviews with experts, other videos, books, and blog posts. The highest number of external resources belonged to the IntroPsych course with 168 external videos and 125 external online resources.

Instructors of soft MOOCs encouraged students to embrace different or contradictory viewpoints regarding course topics. An expansive curriculum allowed students to use course topics as a starting point and "challenge themselves to go deeper" (Instructor interview, AboriginalEd) if curricular content was already familiar to them. Exposing learners to contextual differences in viewpoints was a goal echoed by the MentalHealth instructor, given that the course included material from different countries.

Hard MOOCs included fewer external resources and adopted a more linear approach to curriculum design. When asked about the likeliness of students in introductory statistics courses facing 
opposing perspectives, the Stats MOOC instructor explained: "I don't think that there is that much controversy at this level. Where there is controversy, it is too advanced."

The two programming MOOCs were taught by the same instructors and shared a suggested textbook, links to e-books, and three websites. While external resources were fewer in quantity compared to soft MOOCs, students in Stats, Programming1, and Programming2 courses shared their lecture notes or codes in wiki spaces, so that other students could use the material if needed. Instructors in the Programming1 course encouraged learners to contribute to the course wiki:

If you've recently solved a tough installation issue or gotten helpful advice about a programming exercise or the video lectures or some other facet of the course, please take some time to help out your fellow classmates by writing about it. Feel free to create pages, clarify answers, and otherwise take ownership of these pages (Programming1, Course wiki).

Overall, curricular content and resources in these six hard and soft MOOCs were consistent with Neumann's (2003) categorization. Hard MOOCs represented expert knowledge and promoted mastery of concepts and professional skills. Soft MOOCs juxtaposed several viewpoints and promoted a critical stance towards learning. Note that the three hard MOOCs were introductory courses that lay the foundation for more advanced courses, which could also explain less emphasis on competing perspectives.

\section{Range of Assessment Methods}

Each MOOC incorporated a variety of graded and non-graded assessment methods ranging from multiple-choice questions to essays. Hard MOOCs used frequent non-graded assessment, such as in-video quizzes, with the majority of them being problems: 244 problems vs. 63 recall questions across three hard MOOCs. Soft MOOCs had 140 recall in-video quizzes. We noted a smaller number of nonrecall in-video quizzes, and 13 comprehension questions in soft MOOCs.

In this study, we identified an assessment method as formative if the outcome of the assessment informed teaching and learning. Learners in hard MOOCs had ample opportunity to use graded and non-graded assessments to master course material. The course logistics page of Programming1 MOOC indicated: "You can submit each exercise up to 5 times and we will use the highest grade from all of your submissions."

We also categorized assessment methods based on assessment mode. As Table 1 shows, peerassessed and automatically-graded assessments formed almost all MOOC assessments for hard and soft MOOCs. Programming2 and Stats MOOCs dedicated at least $20 \%$ of the final grade to peerassessment.

For soft MOOCs, the proportion of peer-assessed to automatically-graded assessment was different in each course. MentalHealth exclusively used peer-assessment while IntroPsych relied on automatic-grading. Instructor interview and curriculum documents, however, revealed that the IntroPsych MOOC employed a sophisticated form of automatic-grading implemented via a web-based tool that scaffolded active learning. For each question in this assessment tool, learners first answered the question in their own words. Then, they were shown four alternatives among which one was the correct answer. A wrong answer took learners to the relevant course material and allowed them to try the question a second time. 
Table 1. Graded assessment in six MOOCs

Assessment Mode (\% of final grade)

\begin{tabular}{|c|c|c|c|}
\hline Disciplinary Category & Title & Peer-assessed & Automatically-graded \\
\hline \multirow{6}{*}{ Hard } & \multirow{3}{*}{\multicolumn{2}{|c|}{ Programming 1}} & Final exam (25\%) \\
\hline & & & Three assignments (40\%) \\
\hline & & & Seven exercises $(35 \%)$ \\
\hline & & & Four exercises $(60 \%)$ \\
\hline & Programming2 & Coding assignment (20\%) & Assignment (20\%) \\
\hline & Stats & Two assignments (30\%) & Seven exercises $(70 \%)$ \\
\hline \multirow{4}{*}{ Soft } & MentalHealth & Three essays (100\%) & Bonus quiz (10\%) \\
\hline & \multirow{2}{*}{ AboriginalEd } & \multirow{2}{*}{ Essay $(50 \%)$} & Two quizzes (40\%) \\
\hline & & & Discussion participation (10\%) \\
\hline & IntroPsych & Essay (10\%) & Two web-based tests (90\%) \\
\hline
\end{tabular}

Peer-assessed components in all MOOCs had accompanying rubrics allowing the students to refine their answers before submitting their assignment. Learners in AboriginalEd, Stats, Programming2, and MetalHealth MOOCs only received full score for their peer-assessed assignments if they assessed their peers' submissions. Points were deducted for those learners who just submitted their own assignment. These rubrics also guided the peer-assessment process. Hard MOOCs included practice problems, while peer-assessed assignments in soft MOOC were essays.

In one peer-reviewed assignment in MentalHealth MOOC students completed this assessment task: "Write a commentary on how the following terms reflect differences in the way societies have viewed mental health and illness over time: Lunatic asylum; Insane asylum; Mental Hospital; Mental health centre." In the assignment, the instructor emphasized that "There is not a single correct answer to the questions-students should be evaluated based on their ability to apply relevant material from the course to their answer" (Curriculum documents, MentalHealth).

To examine how assessment methods related to learning outcomes of each MOOC, we juxtaposed MOOC learning outcomes and assessment methods for each of the six MOOCs. Assessment in hard MOOCs included problems and coding exercises, in the form of quizzes and assignments, while in soft MOOCs, learners had at least one assignment in the form of a short essay. Assignments and quizzes in the Stats MOOC addressed different learning outcomes: quizzes helped learners to master course content, while assignments that increased in complexity provided learners with an opportunity to, first, apply their knowledge and, eventually, interpret the results of a statistical analysis. The two Programming MOOCs included a variety of coding exercises that allowed learners to develop their coding skills, with Programming 2 MOOC providing a peer-assessment opportunity for learners that mirrored expected competencies in professional practice. The Programming 2 instructor further explained that code reviews:

... are common in the workplace and before a piece of code would become part of the main system, it is very typical for that code to be reviewed by one of your colleagues. In a code review, you might give a suggestion for a different way, a simpler way of doing it or it might be a formality and say that you have checked all the boxes, you met the style guidelines, it looks the way it is expected to. (Programming 2, Instructor interview) 
Three peer-reviewed short-essay assignments in MentalHealth MOOC enabled learners to apply the course content to their own interests and supported a reflective stance towards the social context of practice as relevant to mental health professionals. Assignments were open-ended, and the syllabus stated: "There is not a single correct answer to the questions-students should be evaluated based on their ability to apply relevant material from the course to their answer." (Course Syllabus, MentalHealth). The last assignment specifically addressed one of the learning outcomes where learners evaluated contextual social factors that influenced mental illness and mental health. In AboriginalEd MOOC, one ethnographic essay, discussion in the course forum, and four non-graded reflective activities encouraged learners to evaluate available evidence and use it to construct arguments. For peerassessment, learners were reminded to pay attention to how evidence supported a writer's argument rather than to judge how much the argument agreed with their own views. Argumentation and critical thinking skills in IntroPsych MOOC were fostered through a short essay. Learners could practice active learning and critical thinking while answering specially designed multiple-choice questions in mTuner. A sophisticated web-based approach to assessment, mTuner assessment tool embeds active learning in a multiple-choice format. mTuner is conceptualized and implemented by the instructor's research lab to encourage actively engaging with learning while being assessed. Here is a description of mTuner obtained from the "Active Learning: Online Redesign" project website (http://alor.onlinelearning.utoronto.ca/web-application-development):

mTuner assessment tool incorporates all of the existing research on "assessment FOR learning" to provide the most powerful learning context possible. Students are never more engaged than when their learning is being assessed. This assessment tool asks students to first generate answers, it supports the deepest learning experience, informs students when their answers are correct to reinforce accurate learning, provides students with hints and gives them a second chance when they initially are incorrect. It corrects misconceptions, and by summarizing the correct answer to every question before moving on, it deepens the learning experience.

For each mTuner question, learners first attempted to answer the question in their own words. Then, they were shown four alternatives among which one was the correct answer. Upon choosing the correct answer, learners were presented with an explanation about that answer. A wrong answer took learners to the relevant course material and allowed them to try the question a second time.

\section{Interaction Design}

We focused on students and instructors' interaction on the platform-provided discussion tool. IntroPsych MOOC included external components, for example, that were heavily reliant on peer interaction and collaboration.

Purpose of interaction. As extracted from course documents and instructor interviews, studentstudent and student-instructor interaction served numerous purposes (see Table 2). Note that examining the content of the discussion forum posts was out of the scope of this particular study but will be considered for future analysis. 
Table 2. Purposes of interaction in the six MOOCs

\begin{tabular}{ccccccc}
\hline & & \multicolumn{5}{c}{ Purpose of Interaction } \\
\cline { 2 - 7 } & & Q\&A & Discussion & Diversity & Empowerment & $\begin{array}{r}\text { Community } \\
\text { Feedback to } \\
\text { Instructor }\end{array}$ \\
\hline \multirow{2}{*}{ Hard } & Programming1 & $\checkmark$ & & $\checkmark$ & $\checkmark$ \\
MOOCs & Programming2 & $\checkmark$ & & & $\checkmark$ & $\checkmark$ \\
& Stats & $\checkmark$ & & $\checkmark$ & $\checkmark$ & $\checkmark$ \\
Soft & MentalHeath & $\checkmark$ & $\checkmark$ & $\checkmark$ & $\checkmark$ & $\checkmark$ \\
MOOCs & AboriginalEd & $\checkmark$ & $\checkmark$ & $\checkmark$ & $\checkmark$ & $\checkmark$
\end{tabular}

Asking and answering questions was a common purpose of discussion forum use in Soft and Hard MOOCs. The other common purpose was community building, which, in the case of the MentalHealth MOOC allowed different stakeholders to bring various perspectives to the conversations. For Soft MOOCs, discussion and idea sharing were indicated as other reasons for participation. Exposure to diversity, nevertheless, was unique to Soft MOOCs. Such emphasis links back to the curricular content of soft disciplines, validating the diversity of ideas and perspectives. Empowering learners to take action by engaging them in discourse was the ultimate rationale for discussion participation in the AboriginalEd MOOC.

Regardless of the relevance of students' discussion forum participation to their learning, course announcements, curricular documents, and instructor interviews showed that peer interaction was valued and encouraged in all six MOOCs. Consider the following announcement shared with MentalHealth learners as one example: "We hope that you will take the time to not only watch the lectures but also participate in the forums by asking and answering questions and sharing your thoughts." (Course announcement)

Choice of discussion topics, learning activities that encouraged learners to share their perspectives with each other, and providing questions that instigated conversation among learners were recognized by the MentalHealth and the IntroPsych instructors as strategies to increase peer interaction and learner engagement in course discussion. Reflecting on ways to encourage learner participation in discussions and to promote deeper thinking, the Stats instructor entertained the potential of integrating discussion prompts so that learners could exchange ideas about concepts covered in a given week of the course beyond the scope of exercises.

\section{Discussion forum structure.}

Overall, discussion forum structure across MOOCs mirrored course content, activities, and assignments with each component of the course being assigned a sub-forum. Such structure facilitated learners posting their questions and comments to an appropriate sub-forum, which in turn, allowed the instructors to monitor ongoing discussions more efficiently. Meta sub-forums and threads created by the instructors sometimes moved beyond course components to foster deeper discussions. In the IntroPsych MOOC, for instance, a member of the instructional team initiated a Summary thread and a Question of the Week thread in the course sub-forums. 
A common issue brought up by the MOOC instructors was that learners posted similar questions or comments in different threads, which hindered the instructional teams' efforts to effectively monitor the discourse and address questions or comments. Having faced this problem in the first offering of Programming1 where learners created threads with repetitive and/or overlapping content, the instructors implemented a highly structured discussion forum design in Programming 2 and in the second offering of Programming1 and only monitored posts that were created in an appropriate subforum. The instructors described their discussion forum design rationale:

Instructor1: In the first one, ... we had these discussion groups per assignment and per exercise... And that turned out to be so free form that people posted the same question literally dozens of times. And it just overwhelmed us with questions and we eventually gave up in trying to keep up with all the different areas and we focused on the ones that were posted in the right place. And then Instructor2 decided that we were going to change.

Instructor2: The goal the second time around was to make it clear exactly which sub-forum you would post a question in... It was all very targeted and for something like the exercises we had sub-forums by question... You had to drill down but when you got there, you could more easily spot the question you were asking. (Instructors' interview, Programming1\&2)

Learners could deviate from the initial discussion forum structure in IntroPsych, AboriginalEd, and MentalHealth MOOCs. For instance, students in the MentalHealth course could respond to weekly questions posted by the instructor or according to the Course Syllabus "start discussions using their own questions." The instructor encouraged learners' unprompted contributions to the discussion forum in a message shared in the second week of the course: "I had put in some special questions but from what I can tell, you guys don't need my help, there are terrific discussions happening" (Prologue to Lecture 2, MentalHealth).

\section{Instructional presence in course discussions.}

While the quantity of forum posts appeared overwhelming and monitoring the threads was time consuming, instructors described their strategies for monitoring the discussion forum and commented when needed. Only one instructor tackled the discussion forums alone. The other instructors formed an instructional team with designated assistants who scanned discussion forum posts along with the instructor, answered questions when needed, or let the instructor know if direct intervention was required.

Monitoring the course discussion forum served three purposes: answering questions, checking the relevance and accuracy of content contributed to the forums, and detecting potential deviances from discussion forum code of conduct. In the second offering of Programming1, a number of learners who had completed the first offering were invited to join the instructors as Community Teaching Assistants (CTAs). According to the instructors, CTAs effectively monitored discussion threads and answered questions. Programming MOOC instructors also focused their attention to sub-forums, such as assignments, where multiple students could benefit from their replies to questions: "The areas that we monitored were heavily trafficked but we also had a lot of bang for the buck where answering a question that was confusing to a lot of people had a big impact." (Instructors' interview, Programming1\& 2).

In their interviews, instructors reflected on how their level of involvement in course discussions impacted learners' participation. The AboriginalEd MOOC instructor kept an active presence in 
discussion forums following Programming $1 \& 2$ MOOC instructors' advice, and believed that learners would become more engaged in discussions knowing that the instructor was actually following the conversation. Only one MOOC instructor, Stats, speculated that their presence in the discussion forum might have shortened the threads as learners would see the correct answer and not continue the discussion.

Beyond commenting in discussion threads, MOOC instructors sometimes intervened to address conflicts. Instances of conflict instigated by controversial topics existed in all three Soft MOOCs. Instructors addressed content-related conflicts by commenting in relevant threads to provide further information, creating response videos, or sending messages to learners through course announcements. After discussions regarding a controversial topic led to a heated argument, in addition to providing a commentary, the IntroPsych MOOC instructor communicated the following message to learners:

I personally don't want to dwell on this issue too long; there are too many other interesting things to be discussing as well, but I don't want to blow it off either. Pondering how we came to be is a big part of the human experience, and I do think about these issues often. So it's worth discussion, in a respectful way, with open minds and big ears. (Announcement, IntroPsych)

\section{DISCUSSION AND IMPLICATIONS}

We examined course design in six U of T MOOCs using an epistemologically informed framework (Neumann et. al., 2002) to guide our analysis along two broad disciplinary categories of hard and soft. We identified differences and similarities across four dimensions in MOOCs belonging to different disciplines: learning outcomes, curriculum and content, assessment, and interaction design. Findings of our study demonstrated that MOOC instructors designed their courses with the intention of actively engaging MOOC learners within the inherent technical constraints of MOOC environments, a situational factor beyond their course design decision-making. With the underpinning universal course template, the six courses appeared unvaried in high level design and structure. However, instructors of each course adapted the existing tools of the Coursera platform as much as possible to foster desired learning outcomes for their diverse learners. When possible, as in the case of IntroPsych course, other tools were integrated into the platform to enrich the learning experience.

\section{MOOC Learning Outcomes Related to Disciplinary Expectations}

Learning outcomes of the six MOOCs reflected broad cognitive competencies that each course promoted. Soft MOOCs explicitly emphasized the importance of critical thinking, evidence-based argumentation, and evaluation of evidence. Developing knowledge of fundamental concepts and methods of a field and, subsequently, applying that knowledge in solving problems, characterized the learning outcomes of hard MOOCs. The emphasis on critical thinking skills and argumentation in soft fields, and on deep knowledge of principles and being skilful in the application of methods in hard disciplines, are highlighted in conceptual papers (Neumann et al., 2002) and studies that examined instructors' views of discipline-related learning goals in undergraduate education (Hativa, 1997).

While differences in high level learning outcomes existed between hard and soft MOOCs, we observed commonalities with respect to cognitive skills with broad applications. The Stats MOOC instructor, a hard course, noted the importance of critical thinking, which, in higher education is recognized as a trans-disciplinary skill (Krause, 2014). 


\section{Content and Curriculum}

Curricular content and instructor's beliefs about disciplinary ways of knowing and methods for authenticating knowledge assertions, revealed differences between soft MOOCs-IntroPsych, AboriginalEd, and MentalHealth—and hard MOOCs_Stats, Programming1, and Programming2. Synthesizing existing conceptions of teaching in different disciplines (Neumann et al., 2003), courses associated with hard disciplines tend to have structured and sequenced content. In soft disciplines, competing paradigms often coexist, leading to courses that have less structured content and showcase more of a spiral curriculum. Soft MOOCs instructors all communicated with learners the importance of context with respect to content. However, the three hard MOOCs were introductory courses where content knowledge is established, so that also influenced design decisions. Understanding the curriculum and content design in more advanced hard MOOCs, in a similar MOOC platform, is a compelling line of future research.

Student-centeredness, within the curricular context of a course, was another characteristic of curricular content in soft MOOCs. All three soft MOOC instructors, as explained in the findings section, created new content in response to discussions around existing curricular content. In these courses, students actively shaped course content and built on the foundation of the instructors' original visions.

Course content in this study was examined from a discipline specific epistemological perspective, which differentiates our findings from the work of Swan et al. (2014), where content was rated on a continuum of abstract to concrete regardless of a course's disciplinary affiliation. Swan et al. (2014) also defined structured-ness of a MOOC in terms of consistent organization and presentation of content. Using such criteria, we could not differentiate among the hard and soft MOOCs, as they would differ only minimally. Instead, informed by our conceptual framework, we interpreted structured-ness as the degree to which the original course content reflected the characteristics of disciplinary knowledge (Donald, 1995) and yielded itself to tangential discussion and opportunistic expansion. Building on the learning outcomes of their MOOCs, instructors in this study constructed their course content in accordance with disciplinary expectations.

\section{Assessment Methods}

All six MOOCs utilized graded and non-graded assessment methods. For hard MOOCs, with more emphasis on mastery of methods and application of knowledge, practice problems comprised the bulk of non-graded assessments. Hard MOOCs also extended the opportunity for formative assessment to some of their quizzes and assignments, where learners could submit their answers multiple times. Jessop and Malekar (2016) have reported similar findings with respect to the use of formative assessment in science courses.

The type and number of graded assessments in these six MOOCs reflected Neumann et al's (2002) characterization of assessment in different disciplinary categories. Soft MOOCs had fewer graded assessments compared to hard MOOCs. Assessment methods in hard MOOCs were quantitative, e.g. mathematical problems and coding assignments. For soft MOOCs, specifically AboriginalEd and MentalHealth, short essays encouraged learners to craft evidence-based and contextualized arguments. With formative assessment far more explicitly evident in hard MOOCs, we propose that soft MOOC instructors consider ways to include scaffolded opportunities for formative assessment where learners can self-assess their work and self-diagnose areas of improvement.

An unexpected observation was that $90 \%$ of students' final grade in IntroPsych, a soft MOOC, was implemented as automatically-graded questions. An examination of course assessment, however, revealed that one of the non-graded course activities, implemented as an external web-based tool, 
utilized a technological system that allowed learners to experience an authentic research cycle. Another assessment design feature in the IntroPsych MOOC was a web-based assessment tool that embedded active learning in a seemingly multiple-choice format. In MOOC-like learning contexts, where the ratio of learners to instructional team members does not allow frequent personalized feedback, such assessment tools that add a formative element to standard multiple-choice questions can engage learners in monitoring and recalibrating their understanding of course material.

Peer-graded assignments were included in five MOOCs. Learners received detailed instructions on the process of peer-assessment and were also given grading rubrics and guidelines. Some of the MOOC instructors used strategies to encourage learners to actively engage in peer-assessment. For example, a full score for a peer-graded assignment was only awarded if a learner assessed the work of their peers.

Peer-assessment is a fertile ground for research in MOOCs, or in large enrollment classes in general (Paré, et al, 2015). Researchers have, for example, conducted empirical studies to examine the implications of rubric construction on completion rate and quality of peer feedback (Yousef, Wahid, Chatti, Schroeder, \& Wosnitza, 2015). We acknowledge that without analyzing actual peer assessment data in this current study, we cannot comment on the effectiveness of such motivational strategies.

Assessment methods in each MOOC aligned well with their identified learning outcomes. While none of the MOOC instructors indicated following a specific model, such as backward design (Wiggins \& McTighe, 2005), to establish such alignment, we posit that MOOC instructional design training and support in this particular university stressed the importance of using learning outcomes as the foundation upon which instructional activities and assessment methods are built.

\section{Interaction Design and Instructor Involvement}

Participation in discussion forums was encouraged in the six MOOCs, even though interactions served different purposes in hard and soft MOOCs: soft MOOCs emphasized discussion and exposure to a variety of contexts and perspectives while hard MOOCs had more emphasis on question and answer type interactions. Aggregate numbers of posts in the discussion forum of the MOOCs included in this study are reported in "Open U of Toronto MOOC Initiative" reports (2014). However, calculating the amount of interaction corresponding to each purpose may be carried out via content analysis in a future study.

Regarding strategies for increasing participation in the discussion forums, instructors used course announcements to encourage learner participation. The six MOOCs in this study did not incorporate deliberate treatments, such as customized messages sent to experimental learner groups. Yet lack of such treatments does not translate into design flaw or drawbacks. The effectiveness of targeted treatment to enhance participation in MOOCs is far from established. For example, in two studies, Kizilcec, Schneider, Cohen, and McFarland (2014) observed an adverse impact for persuasive emails sent to learners where learners who received neutral emails reminding them of the existence of a discussion forum, participated in higher rates compared to learners who received persuasive emails that highlighted the importance of individual or collective learning achieved through participation in discussions.

The level of instructors' presence in discussion forums and its impact on the length of discussion threads was a concern for one of the instructors, reflecting the findings of Mazzolini and Maddison (2007). As well, Tomkin and Charlevoix (2014) investigated the role of MOOC instructor presence on learner engagement in discussion forums in an Environmental Science MOOC where learners were assigned randomly to two groups: a control group with no instructional presence, and a treatment group 
with instructional presence in discussion threads. The treatment group and the control group did not differ in participation rates in course discussions. In our study, the total number of posts in course discussion forums varied between 5,000 and 31,000 in all six MOOCs. Yet a clear distinction between the number of posts in hard and soft MOOCs was not evident. Programming1, a hard MOOC, had more than 25,000 posts while learners in MentalHealth contributed a total number of 11,700 discussion posts.

Beyond demonstrating higher number of learners in soft MOOCs who posted at least once in any discussion thread, our numerical findings from discussion forum data were inconclusive in supporting a distinction between hard and soft MOOC with regards to students and instructors' participation and contribution to MOOC discussion threads. Specifically, contrary to Mazzolini and Madison's (2007) study, we found that median length of threads with any instructor involvement was higher in all MOOCs than threads with no instructor involvement. Further research, such as a study underway by Chandrasekaran et al. (2015), is needed to investigate how instructional presence in MOOC discussion forums can be supported to have more positive learner impact.

\section{SIGNIFICANCE}

To explore variations in MOOC design we mapped the design of teaching and learning components of MOOCs from various disciplines to a widely-used framework for understanding potential differences and similarities across MOOCs. We emphasize, again, that Neuman et al.'s (2002) framework provided an analytical lens through which we recognized main dimensions of teaching and learning rather than prescribing our search for expected differences or commonalities. Few studies have formally examined pedagogical design considerations of MOOCs (Swan et al., 2014). Studies of instructional presence within a MOOC context (Chandrasekaran et al., 2015), or comparing learner engagement in MOOCs differing in their level and topic (Cofrin, Corrin, Barba, \& Kennedy, 2014) are, at the time of reporting this study, starting to emerge in MOOC literature. With the awareness of how pedagogical components of MOOCs may vary from course to course and may reflect underlying disciplinary assumptions, our next step is to examine interaction design in MOOCs to probe the scope and depth of student-student and student-instructor interaction.

At least one instructor in this study raised concerns about the lack of pedagogical models for MOOC design; for example, interaction models that promote learning. Successful integration of active learning in high-enrolment undergraduate courses (Drinkwater et al., 2014) could provide MOOC instructors with design ideas. In the present study, alternative assessment approaches that were integrated in the IntroPsych MOOC, for example, show that there is potential for fostering active learning in large and diverse learning environments similar to MOOCs.

One implication of this research is to propose opportunities for fostering active learning and deep, topic-related discussions by adopting novel pedagogical approaches informed by practices of the extant disciplines or adapted from successful models in other disciplines. In this paper, we took one step forward in deconstructing curriculum design and implementation in six MOOCs representing a range of disciplinary affiliation to identify instances of such practices.

MOOC instructors who participated in this study attempted to foster ways of knowing, relevant perspectives, professional practice, fundamental skills, and foundational knowledge in their subject domain and within the parameters of a generic MOOC platform. Several indications of promising practice have emerged from this study. First, MOOCs can be a sand box for testing innovative pedagogical practice (Fischer \& Wolf, 2015) to further inform teaching and learning in on-campus courses. Second, the need for scalability may serve as a catalyst for instructors to explore design 
strategies outside of their disciplinary traditions. Finally, the work of MOOC instructors at the University of Toronto shows early signals of the value of exposure to pedagogical approaches of instructors from other subject areas. These instructors have had access to both formal and informal professional development activities that facilitate sharing of experience of both the process and outcomes (e.g., the role of peer-assessment in fostering critical thinking). Creating further opportunities for exchange of ideas both within and across discipline areas may serve to expand the repertoire of approaches to innovative curricular design.

\section{ACKNOWLEDGEMENT}

We would like to thank the MOOC instructors who participated in this study. We also acknowledge the University of Toronto administrators who encouraged and supported this research initiative.

Hedieh Najafi is a researcher, Online Learning Strategies at the University of Toronto, Canada.

Carol Rolheiser is a Professor at the Ontario Institute for Studies in Education and is the Director of the Centre for Teaching Support \& Innovation at the University of Toronto, Canada.

Stian Håklev is a postdoctoral researcher at École Polytechnique Fédérale de Lausanne Switzerland.

Laurie Harrison is the Director, Online Learning Strategies at the University of Toronto, Canada.

\section{REFERENCES}

Barberà, E., Layne, L., \& Gunawardena, C. (2014). Designing online interaction to address disciplinary competencies: A cross-country comparison of faculty perspectives. The International Review Of Research In Open And Distributed Learning, 15(2).

Biglan, A. (1973). The characteristics of subject matter in different academic areas. Journal of Applied Psychology, 57(3), 195.

Coffrin, C., Corrin, L., de Barba, P., \& Kennedy, G. (2014). Visualizing patterns of student engagement and performance in MOOCs. In proceedings of the Fourth International Conference on Learning Analytics and Knowledge (pp. 83-92). New York, NY, USA: ACM.

Cox, K., Imrie, B. W., Miller, A., \& Miller, A. (2014). Student assessment in higher education: $A$ handbook for assessing performance. London: Routledge.

Chandrasekaran, M. K., Ragupathi, K., Kan, M.-Y., \& Tan, B. C. (2015). Towards feasible instructor intervention in MOOC discussion forums. Paper presented at the 36th International Conference on Information Systems, Fort Worth, TX.

Donald, J. G. (1995). Disciplinary differences in knowledge validation. New Directions for Teaching and Learning, 1995(64), 6-17.

Drinkwater, M. J., Gannaway, D., Sheppard, K., Davis, M. J., Wegener, M. J., Bowen, W. P., \& Corney, J. F. (2014). Managing active learning processes in large first year physics classes: The advantages of an integrated approach. Teaching and Learning Inquiry: The ISSOTL Journal, 2(2), 75-90.

Fischer, G., \& Wolf, K. D. (2015). What can residential, research-based universities learn about their core competencies from MOOCs (Massive Open Online Course). In H. Schelhowe, M. Schaumburg, and J. Jasper (Eds.) Teaching is touching the future - Academic teaching within and across disciplines (pp. 6575). Universitätsverlag Webler, Bielefeld,.

Garrison, D. R., Anderson, T., \& Archer, W. (2010). The first decade of the community of inquiry framework: A retrospective. The Internet and Higher Education, 13(1), 5-9.

Gorsky, P., Caspi, A., Antonovsky, A., Blau, I., \& Mansur, A. (2010). The relationship between academic discipline and dialogic behavior in open university course forums. The International Review of Research in Open and Distributed Learning, 11(2), 49-72. 
Hativa, N. (1997, March). Teaching in a research university: Professors' conceptions, practices, and disciplinary differences. Paper presented at the annual meeting of the American Educational Research Association. Chicago.

Jessop, T., \& Maleckar, B. (2016). The influence of disciplinary assessment patterns on student learning: A comparative study. Studies in Higher Education, 41(4), 696-711.

Kizilcec, R. F., Schneider, E., Cohen, G. L., \& McFarland, D. A. (2014). Encouraging forum participation in online courses with collectivist, individualist and neutral motivational framings. In U. Cress and C. D. Kloos (Eds.), EMOOCS 2014, Proceedings of the European MOOC Stakeholder Summit (pp. 80-87).

Krause, K. L. D. (2014). Challenging perspectives on learning and teaching in the disciplines: the academic voice. Studies in Higher Education, 39(1), 2-19.

Laird, T. F. N., Shoup, R., Kuh, G. D., \& Schwarz, M. J. (2008). The effects of discipline on deep approaches to student learning and college outcomes. Research in Higher Education, 49(6), 469-494.

Lindblom-Ylänne, S., Trigwell, K., Nevgi, A., \& Ashwin, P. (2006). How approaches to teaching are affected by discipline and teaching context. Studies in Higher education, 31(3), 285-298.

Mazzolini, M., \& Maddison, S. (2007). When to jump in: The role of the instructor in online discussion forums. Computers \& Education, 49(2), 193-213.

Neumann, R. (2003). A disciplinary perspective on university teaching and learning. Access and Exclusion, 2, 217245.

Neumann, R., Parry, S., \& Becher, T. (2002). Teaching and learning in their disciplinary contexts: A conceptual analysis. Studies in Higher Education, 27(4), 405-417.

Norton, L., Richardson, T. E., Hartley, J., Newstead, S., \& Mayes, J. (2005). Teachers' beliefs and intentions concerning teaching in higher education. Higher education, 50(4), 537-571.

Open U of Toronto MOOC initiative: Report on second year of activity. (2014). University of Toronto. Retrieved from: http://www.ocw.utoronto.ca/open-utoronto-mooc-initiative-year-two/

Paré, D. E., Collimore, L.-M., Joordens, S., Rolheiser, C., Brym, R., \& Gini-Newman, G. (2015). Put students' minds together and their hearts will follow: Building a sense of community in large-sized classes via peer-and self-assessment. Toronto, ON: Higher Education Quality Council of Ontario.

Pearson, M. L.; Albon, S. P.; \& Hubball, H. (2015). Case study methodology: Flexibility, rigour, and ethical considerations for the scholarship of teaching and learning. The Canadian Journal for the Scholarship of Teaching and Learning, 6(3). Article 12. Retrieved from: http://ir.lib.uwo.ca/cjsotl_rcacea/vol6/iss3/12

Postareff, L., Virtanen, V., Katajavuori, N., \& Lindblom-Ylänne, S. (2012). Academics' conceptions of assessment and their assessment practices. Studies in Educational Evaluation, 38(3), 84-92.

Stake, R. E. (2006). Multiple case study analysis. New York, NY: Guilford Press.

Swan, K., Bogle, L., Day, S., van Prooyen, T., \& Richardson, J. (2014). Assessing MOOC pedagogies. World Conference on Educational Multimedia, Hypermedia and Telecommunications, 2014(1), 1018-1026.

Tomkin, J. H., \& Charlevoix, D. (2014, March). Do professors matter?: Using an a/b test to evaluate the impact of instructor involvement on MOOC student outcomes. Proceedings of the first ACM Conference on Learning@ Scale Conference (pp. 71-78).

Trigwell, K., \& Prosser, M. (2004). Development and use of the approaches to teaching inventory. Educational Psychology Review, 16(4), 409-424.

Wiggins, G. P., \& McTighe, J. (2005). Understanding by design. Alexandria, VA. ASCD.

Yousef, A. M. F., Wahid, U., Chatti, M. A., Schroeder, U., \& Wosnitza, M. (2015). The effect of peer assessment rubrics on learners' satisfaction and performance within a blended MOOC environment. Proceedings of the 7th International Conference on Computer Supported Education, Vol. 2 (pp. 148-159). Lisbon, Portugal. 
Copyright for the content of articles published in Teaching \& Learning Inquiry resides with the authors, and copyright for the publication layout resides with the journal. These copyright holders have agreed that this article should be available on open access under a Creative Commons Attribution License 4.0 International (https://creativecommons.org/licenses/by/4.0). The only constraint on reproduction and distribution, and the only role for copyright in this domain, should be to give authors control over the integrity of their work and the right to be properly acknowledged and cited, and to cite Teaching \& Learning Inquiry as the original place of publication. Readers are free to share these materials-as long as appropriate credit is given, a link to the license is provided, and any changes are indicated. 